\title{
QUESTÃO AGRÁRIA E EDUCAÇÃO DO CAMPO: CONTROVÉRSIAS E PERSPECTIVAS
}

\author{
M. A. AZEVEDO', I. R. B. AZEVEDO² \\ ${ }^{1}$ Instituto Federal do Rio Grande de Norte, ${ }^{2}$ Universidade Federal do Rio Grande do Norte \\ marcio.azevedo@ifrn.edu.br
}

Submetido 07/10/2014 - Aceito 17/01/2018

DOI: $10.15628 /$ holos. 2018.1700

\section{RESUMO}

Objetiva analisar as controvérsias e perspectivas acerca da questão agrária no Brasil. Foram utilizados procedimentos teórico-metodológicos da revisão de literatura e da análise documental. Percebe-se que o Brasil tem suas raízes históricas, políticas, econômicas e culturais marcadas pela dimensão e questão agrária, sendo possível identificar diferentes momentos, quais sejam do período de transição da Monarquia à República, do Estado oligárquico ao populista, deste último ao militar, durante a crise do militarismo e nos movimentos e partidos que desde o final dos anos de 1970, vêm lutando para que o Estado formule e implemente políticas públicas de natureza agrária que desenvolvam ações socialmente referenciadas. Concluise que as orientações políticas acerca da educação rural vêm mostrando a necessidade de se melhorar a qualidade social da educação nos países LatinoAmericanos, onde os índices de pobreza ainda são elevados e a questão do acesso educacional ainda continua pendente. Em meio às controvérsias, percebese que a partir dos anos de 1980 o movimento social e sindical do campo foi se fortalecendo em sua capacidade de luta e de organização político-ideológica, acentuando-se em 1990, quando se desencadearam discussões e proposições acerca da educação para os camponeses e trabalhadores rurais. Considerada uma conquista histórica, a política de educação do campo se tornou oficialmente pública e governamental em 2002, por meio da aprovação das Diretrizes Operacionais para a Educação Básica nas Escolas do Campo.

PALAVRAS-CHAVE: Educação do Campo, Questão agrária, Direitos, Espaços em disputa.

\section{AGRARIAN ISSUE AND FIELD EDUCATION: CONTROVERSYS AND PERSPECTIVES}

\begin{abstract}
Aims to analyze the controversies and perspectives about the agrarian question in Brazil. Theoretical and methodological Procedures were used for literature review and document analysis. One realizes that Brazil has its historical roots, political, economic and cultural marked by dimension and by agrarian question, can be identify different moments, namely the transition from monarchy to republic, the oligarchic state populist latter to military during the crisis of militarism and movements and parties since the late 1970s, have been fighting for the state to formulate and implement public policies of agrarian nature to develop socially referenced actions. Concludes that the policy guidelines
\end{abstract}

on rural education have shown the need to improve the social quality of education in Latin American countries, where poverty rates are still high and the issue of educational access is still pending. Amid the controversy, it is clear that from the 1980s the social movement and union field became stronger in their ability to fight and political-ideological, emphasizing in 1990, when triggered discussions and propositions about education for peasants and rural workers. Considered a historic achievement, education policy field officially became public and government in 2002, through the approval of the Operational Guidelines for Basic Education in Rural Sc.

KEYWORDS: Rural Education, Agrarian question, Rights, Spaces in dispute. 


\section{INTRODUÇÃO}

O presente artigo é resultado de produção acadêmico-científica apresentada no Espaço de Diálogos e práticas do Encontro Nacional de Geográficos, realizado no período de 22 a 22 de julho de 2012, no Campus Pampulha da Universidade Federal de Minas Gerais (UFMG), tendo como tema central "entre escalas, poderes, ações, Geografias".

O Brasil tem suas raízes históricas, políticas, econômicas e culturais marcadas pela dimensão e questão agrária, sendo possível identificar diferentes momentos, quais sejam do período de transição da Monarquia à República, do Estado oligárquico ao populista, deste último ao militar, durante a crise do militarismo e nos movimentos e partidos que desde o final dos anos de 1970, vêm lutando para que o Estado formule e implemente políticas públicas de natureza agrária que desenvolvam ações socialmente referenciadas. Para lanni (2004), mesmo com as modificações ocorridas desde a extinção da escravatura, as bases agrárias continuam sendo importantes no Brasil, embora a industrialização e a urbanização, acentuadas desde os anos de 1930, tenham exercido uma influência estrutural no meio rural, tencionando e suscitando uma discussão que imprime à questão e à reforma agrária a compreensão de diferentes concepções que se inserem no cenário socioeconômico brasileiro conforme os projetos sócio-políticos em disputa.

A reforma agrária no Brasil teve a sua mais alta expressão no Estatuto do Trabalhador Rural (1963), estendendo o direito de sindicalização e outras regalias do trabalhador urbano ao assalariado agrícola. Pode-se destacar também o projeto de reforma agrária do próprio poder executivo, constante da Mensagem Presidencial de março de 1964 e que, provavelmente, teria sido aprovado, se o governo Goulart não caísse, deposto por um golpe militar, conforme analisa Ribeiro (2004). Para Martins (2000), é inquestionável também que a CPT e o MST foram importantes protagonistas responsáveis pela inclusão da questão agrária na agenda política do Estado brasileiro, sem que a discussão fosse tratada como um problema residual, esporádico e sem maior importância político-social, como vinha ocorrendo desde a aprovação do Estatuto da Terra. "Fizeram-no, portanto, sem o saber, pela tortuosidade das vias indiretas, por meio das repercussões injustamente negativas de suas ações e não pela via política de quem propõe, assume e administra politicamente a proposta e a conquista" (MARTINS, 2000, p. 21). Ressalta, portanto, que a luta dos movimentos tornou-se maniqueísta e redutiva, visto que desejam promover uma revolução sem dela participar ativa, pública, responsável e politicamente possível e viável, ante o cenário e a realidade agrária que se configurou historicamente no País. 


\section{PARA COMPREENDER A CONCEPÇÃO DE EDUCAÇÃO DO CAMPO}

Analisando os relatórios técnicos de instituições como o IICA, UNESCO e FAO (2005) e da UNESCO (2004a), vimos que as orientações políticas acerca da educação rural vêm mostrando a necessidade de se melhorar a qualidade social da educação nos países Latino-Americanos, onde os índices de pobreza ainda são elevados e a questão do acesso educacional ainda continua pendente. No Brasil, as políticas de educação formuladas e implementadas para o meio rural foram caracterizadas por ações descontínuas, representando "[...] uma fatia muito pequena e mesmo marginal nas preocupações do setor público" (CALAZANS ET. AL., 1981, p. 162). Para Fernandes e Molina (2004), na história da educação brasileira o conceito de educação rural sempre foi associado às condições precárias, atrasadas, arcaicas e com pouca qualidade social, enfatizando que:

A origem da educação rural está na base do pensamento latifundista empresarial, do assistencialismo, do controle político sobre a terra e as pessoas que nela vivem. [...] Enquanto a Educação do Campo vem sendo criada pelos povos do campo, a educação rural é resultado de um projeto criado para a população do campo, de modo que os paradigmas projetam distintos territórios. Duas diferenças básicas desses paradigmas são os espaços onde são construídos e seus protagonistas (FERNANDES; MOLINA, 2004, p. 62).

Percebemos, assim, que a origem da educação rural está associada às concepções socioeconômica, política e ideológica que se desenvolvem no setor e sua diferenciação e/ou relação com o urbano. Para Vale (2005), as características que diferenciam o rural do urbano são sinteticamente:

a) a baixa densidade populacional;

b) o uso econômico predominantemente agropecuário; c) os moradores têm um perfil que se caracteriza pelo pertencimento às pequenas coletividades e às relações particulares com o espaço;

d) a cultura se identifica e representa especificamente o meio rural;

e) os sujeitos se relacionam com a natureza por meio de práticas e de representações particulares, tendo relação com espaço, o tempo, a família, as crenças, os costumes, entre outros aspectos, que se diferenciam da cidade;

f) as vivências coletivas resultam das relações e dos interconhecimentos sociais;

g) menor diferenciação e mobilidade sócio-espacial; posse da terra como o centro do sistema político-econômico. 
Essas características ainda são predominantes em algumas regiões do País, como no Nordeste, mas também essa e outras áreas vêm sofrendo alterações sob a lógica capitalista, como aquelas localizadas no "Norte pioneiro do Paraná, como extensos trechos do Estado de São Paulo, como os campos de arroz e trigo do Rio Grande do Sul apresentam desenvolvimentos diretamente vinculados à expansão do capitalismo (IANNI, 2004, p. 100). Para Reis (2006), não há consenso conceitual e metodológico entre os formuladores de políticas públicas, entre os demógrafos, bem como entre os pesquisadores brasileiros sobre as definições sobre o rural brasileiro. Para o autor, trata-se de uma discussão polêmica e que está longe de ser resolvida, pois, além de vigir uma legislação anacrônica, existem poucos estudos no Brasil voltados para a compreensão da problemática.

Tratando as características que definem o rural, os estudos de Reis (2006) enfatizam que estas se associam aos fatores ocupacionais e ambientais, dependendo do tamanho das comunidades e das diferenças na densidade e diversidade populacionais. Na discussão até aqui, apresentamos a visão de alguns autores sobre as características que podem definir o que é rural, diferenciando-o do urbano. Porém, sobre a definição do que é a cidade, identificamos que a sua concepção é uma invenção do Estado Novo, por meio do Decreto-Lei 311, de 1938, o qual transformou em cidades todas as sedes municipais existentes, independentemente de suas características estruturais e funcionais. Desse modo, pequenos povoados e/ou simples vilarejos transformaram-se em cidades por norma que continua em vigência desde o período pós-64, sobretudo em função do Estatuto da Cidade. "Por exemplo, ao dispensar da exigência de Plano Diretor quase todas as cidades com menos de 20 mil habitantes. Será razoável que no início do século 21 se considere cidade um aglomerado de menos de 20 mil pessoas?" (VEIGA, 2001, p. 3, grifos do autor). Para o autor, as cidades que tem esse perfil são considerados municípios rurais. Veiga (2001) ressalta, ainda, que até o ano de 1938 não havia dispositivo legal que diferenciasse o campo e a cidade. Como já foi dito, foi o Estado Novo que estabeleceu as regras de divisão territorial no Brasil, vigentes até hoje, embora em 1991 o IBGE tenha definido "três categorias de áreas urbanas (urbanizadas, não-urbanizadas e urbanas-isoladas) e quatro tipos de aglomerados rurais (extensão urbana, povoado, núcleo e outros)".

O relatório que instituiu as Diretrizes Operacionais para a Educação Básica nas Escolas do Campo (BRASIL, 2002), ressalta que, apesar de o país ter a sua origem assentada nas bases agrárias, os primeiros textos constitucionais - 1824 e 1891 - sequer mencionaram a educação rural. Analisando essa situação no final do Império e no início da República, período em que se estruturava o sistema de instrução elementar no Brasil, Arroyo (1983, p. 20) enfatiza que:

A classe subalterna não é apenas vítima de um projeto de ideologização tentado pelas classes dominantes, ela é agente histórico, constrói a própria história e se faz a si mesma muito mais do que é feita fora. Vemos a história do período como resultado do confronto entre classes por mais heterogêneas que elas sejam, confronto que se dá inclusive a nível de hegemonia e contra-hegemonia cultural.

Assim sendo, a educação rural foi se condicionando a planos inferiores e, ao longo das décadas, observamos que a organização escolar no campo configurou-se por meio de um modelo unidocente. Para este modelo não é acenado um projeto de mudanças, mantendo-se o atraso como um instrumento de poder, conforme ressalta Martins (1999). 
Nesse cenário, havia também indiferença por parte dos dirigentes brasileiros acerca da necessidade de ter-se um projeto educacional específico para a escola do campo. $O$ debate sobre as especificidades da educação no meio rural somente foi inserida na agenda governamental a partir dos anos trinta, por ocasião do movimento escolanovista, em particular a partir dos anos de 1930. As propostas escolanovistas voltadas ao meio rural, como o ruralismo pedagógico, defendiam a ideia de que a escola deveria respeitar os interesses e as necessidades socioeconômicas e culturais dos sujeitos em suas respectivas localidades, a fim de fixá-los em seu meio (CALAZANS, 2009).

Assim sendo, o ruralismo pedagógico fundamentou-se em alguns aspectos escolanovistas para desenvolver as suas ideias e ações, como a utilização de trabalhos cooperativos, internatos no campo e atividades práticas. Desse modo, foram criadas as Escolas Normais para oferecer preparação especializada para professores de escolas rurais. A primeira experiência brasileira com essa modalidade escolar ocorreu em 1934, no município de Juazeiro do Norte/Ceará (LOURENÇO FILHO, 2001). Estudos sobre a constituição de uma cultura docente para atuar no setor rural, avultam que a "[...] criação da Escola Normal Rural de Juazeiro do Norte trouxe para o interior cearense a possibilidade de contar com professores qualificados e preparados para a educação no campo" (NOGUEIRA, 2008, p. 108).

O Movimento ruralista na década de 1930 estava associado às propostas nacionalistas do período Vargas. "Os discursos de valorização do desenvolvimento do meio rural estavam impregnados de expressões como vocação histórica" (MAGALHÃES JÚNIOR; FARIAS, 2007). A intenção era implementar uma política de valorização do crescimento e desenvolvimento econômico do meio rural, associada à necessidade de conter a migração ao meio urbano, fixando, dessa forma, os sujeitos no campo. Em 1947, por exemplo, a UNESCO orientava sobre a necessidade de a educação rural incluir em seus currículos, aspectos relacionados à melhorias nos métodos de cultivo, de conservação do solo, de restauração e fertilidade, de controle de erosão, bem como sobre o uso de máquinas que substituíssem as ferramentas primitivas numa perspectiva de desenvolvimento (WERLE, 2007).

Para Miguel (2007) o sistema escolar no meio rural brasileiro sempre foi marcado pela precariedade de infraestrutura na rede física, nas condições materiais e pedagógicas, além dos problemas relacionados à formação dos professores. O ruralismo influenciou a construção das primeiras escolas públicas no setor rural, mas o projeto foi marcado por uma visão redentora da educação, idealizando fixar os sujeitos no campo para se evitar o agravamento dos problemas sociais nas cidades, bem como para atender aos setores vinculados à elite urbana e à oligarquia rural que dependiam da mão-de-obra no setor. Para outros críticos, como Saviani (2003), propostas como o ruralismo - entendido como otimismo pedagógico - e que têm fundamentos escolanovistas, não ensejavam pensar a escola como um espaço de formação para a participação política. "De uma preocupação em articular a escola como um instrumento de participação política, de participação democrática, passou-se para o plano técnico-pedagógico" (SAVIANI, 2003, p. 51).

Nos anos de 1940, a discussão sobre a necessidade de um projeto educacional voltado especificamente para o meio rural ganhou evidência na agenda governamental brasileira, por ocasião do Oitavo Congresso Brasileiro de Educação, realizado em Goiânia, em 1942 (SOUZA; 
CABRAL NETO, 2004). Na década anterior, o movimento escolanovista, os problemas sociais vivenciados pelo País nos setores urbano e rural, as reivindicações populares pelo direito à educação e o interesse do empresariado para que houvesse uma capacitação da força de trabalho dos migrantes ou estrangeiros, obrigaram o Estado brasileiro a desenvolver uma série de iniciativas, como a CEAA (1947), sendo o marco das campanhas voltadas especificamente ao meio rural, bem como a ACAR (1948).

Nos anos de 1950 destacam-se a CNER (1952); a CNEA (1958), destinada à educação popular e rural e que desenvolveu uma série de projetos e de programas, como os centros de treinamento para professores rurais; e o SIRENA (1958), que desenvolveu o programa de escolas radiofônicas em todo o País, como decorrência da Campanha de Educação de Adolescentes e de Adultos. "A âncora do Sirena era a Rádio Nacional, no Rio de Janeiro, que se encarregava de radiofonizar e transmitir os programas educativos produzidos por uma equipe pedagógica do Serviço de Educação de Adultos do MEC" (SILVA, 2006, p. 67).

A partir dos anos de 1960, as lutas contra a exclusão social, em particular pelo direito à educação e à reforma agrária, ganham notoriedade e subsidiam inúmeras iniciativas e projetos educacionais. O marco dessa redefinição foi o II Congresso Nacional de Educação de Adultos, tendo como relator o educador Paulo Freire, propondo uma educação popular compreendida como um processo de luta para a subsistência e libertação das classes populares. Associado às experiências e iniciativas desenvolvidas nos anos de 1950-1960, Silva (2006) também enfatiza a criação de três organizações camponesas, quais sejam, o Master (1950); a Ultab (1954); e as Ligas Camponesas (1955). Segundo a autora, essas instituições contribuíram para que as lutas políticas e sociais dos camponeses fossem reconhecidas e respaldassem outros movimentos e instituições sociais e sindicais do campo, como a Contag e o MST.

No que se refere à formulação e à implementação de ações que visassem a uma política específica para o meio rural, identificamos que nos anos de 1970, apesar de a Lei n. 5.692/71 acenar para o atendimento das especificidades das escolas do campo, como a adequação do calendário escolar aos ciclos da colheita, continuamos a testemunhar, na verdade, a implantação e a efetividade de projetos experimentais e, portanto, transitórios, como ocorreu com o POLONORDESTE e o PROMUNICÍPIO. Esses programas, segundo Leite (2002, p. 48), ao subsidiarem os Órgãos Municipais de Ensino, exigiram das unidades de ensino maior controle na organização e gestão escolar, sobretudo no que diz respeito ao cadastramento das escolas, dos alunos e dos professores, como também acompanhamento e distribuição de merenda, além de diagnósticos em relação à escolarização nas comunidades rurais. Essas iniciativas parecem não ter sido suficientes para conter os altos índices de analfabetismo, pois, conforme analisam alguns estudiosos, como Queiroz $(1984 ; 1997)$, as ações não foram além daquelas que se vinham desenvolvendo nos municípios.

A partir dos anos de 1980 o movimento social e sindical do campo foi se fortalecendo em sua capacidade de luta e de organização político-ideológica, que se acentuou em 1990, delineando uma série de discussões e proposições acerca da educação para os camponeses e trabalhadores rurais, tentando superar, desse modo, o contínuo silenciamento presente na agenda governamental brasileira em torno da educação rural, dos seus sujeitos e modos de vida, 
"[...] que se explicitava ora na ausência de uma política pública de educação para o meio rural brasileiro, ora no caráter periférico de suas propostas (SILVA; COSTA, 2006, p. 64).

Nos anos 2000 a denominada política de educação do campo ganhou notoriedade no conjunto das ações governamentais voltadas para a educação. Nessa perspectiva, Silva e Costa (2006, p. 68) ressaltam que esse projeto, decorrente da luta e das reivindicações dos movimentos sociais, conforme mostram Leite (2002), Queiroz $(1984,1997)$ e Silva (2006).

A articulação dos envolvidos na construção dessa proposta política e pedagógica - que perpassa os movimentos sociais e sindicais - promoveu eventos, como seminários estaduais e conferências em âmbito nacional, produziram uma literatura específica sobre o assunto, intensificaram o debate e se apropriaram também de mecanismos legais, como a Constituição Federal (1988) e a LDB - Lei n. 9.394/96 - para discutir, construir e aprovar o seu marco normativo: as Diretrizes Operacionais para a Educação Básica nas Escolas do Campo (BRASIL, 2002). Os estudos de Fernandes (2002, p. 91-92) enfatizam que a "[...] aprovação das Diretrizes representa um importante avanço na construção do Brasil rural, de um campo de vida, onde a escola é espaço essencial para o desenvolvimento humano".

As Diretrizes Operacionais para a Educação Básica nas Escolas do Campo (BRASIL, 2002) apresentam, em 16 artigos, os princípios e procedimentos que podem adequar as escolas do campo às suas especificidades. Ao sugerir a supressão da ideia de educação rural, visto incorporar os espaços da floresta, da pecuária, das minas e da agricultura, além pesqueiros, dos caiçaras, dos ribeirinhos e dos extrativistas. Assim como em outros marcos regulatórios, está determinado nas Diretrizes do Programa, que é dever do poder público assegurar o acesso e a qualidade da educação para todos os sujeitos que moram e trabalham no campo. Afirmam ainda que as escolas do campo devem ter um projeto político-pedagógico que contemple a diversidade e a heterogeneidade em todos os seus aspectos: sociais, culturais, políticos, econômicos, de gênero, geração, etnia, dentre outros.

\section{REFERÊNCIAS}

ARROYO, Miguel. Educação para novas relações de trabalho no campo. (1983) In: SEMINÁRIO DE EDUCAÇÃO NO MEIO RURAL, 1982, ljuí. Anais... ljuí, RS: INEP.

BRASIL. Ministério da Educação. (2002) Diretrizes operacionais para a educação básica nas escolas do campo. Brasília: SECAD.

CALAZANS, Maria Julieta Costa. et al. (1981) Questões e contradições da educação rural no Brasil. In: WERTHEIN, Jorge; BORDENAVE, Juan Díaz. (Orgs). Educação rural no terceiro mundo: experiências e novas alternativas. Rio de Janeiro: Paz e Terra, p. 161-198.

CALAZANS, Maria Julieta. (2009) Para compreender a educação do Estado no meio rural: traços de uma trajetória. Disponível em: <http://www.tvebrasil.com.br/salto/boletins2001/cms/cmstxt1.htm.>. Acesso em: 4 maio 2009. 
FERNANDES, Bernardo Mançano. (2002) Diretrizes de uma caminhada. In: KOLLING, Edgar Jorge; CERIOLI, Paulo Ricardo; CALDART, Roseli Salete. Educação do campo: identidade e políticas públicas. Brasília: Articulação Nacional por uma Educação Básica do Campo. (Coleção Por uma Educação Básica do Campo, 4). p. 89-109.

FERNANDES, Bernardo Mançano \& MOLINA, Mônica Castagna. (2004) O campo da educação do campo. In: JESUS, Sônia Meire Azevedo de; MOLINA, Mônica Castagna (Orgs.). Contribuições para a construção de um projeto de educação do campo. Brasília: Articulação Nacional por uma Educação Básica do Campo. (Coleção Por uma Educação Básica do Campo, 5). p. 53-89.

IANNI, Octavio. Origens agrárias do Estado brasileiro. (2004) São Paulo: Brasiliense.

LEITE, Sérgio Celani. (2002) Escola Rural: urbanização e políticas educacionais. 2. ed. São Paulo: Vozes.

LOURENÇO FILHO, Ruy. (2001) Preparação de pessoal docente para escolas primárias rurais. In: LOURENÇO FILHO, Ruy (Org.). A formação de professores: da Escola Normal à Escola de Educação/Manoel Bergstrom Lourenço Filho. Brasília: INEP; MEC, p. 72-91.

MAGALHÃES JÚNIOR, Antônio Germano; FARIAS, Isabel Maria Sabino de. (2007) Ruralismo, memórias e práticas educativas no cotidiano da primeira Escola Normal rural do Brasil: a Escola Normal do Juazeiro do Norte - CE (1934-1946). In: WERLE, Flávia Obino Corrêa (Org.). Educação rural em perspectiva internacional: instituições, práticas e formação do professor. ljuí: Unijuí. p. 53-78.

MARTINS, José de Souza. (1999) O poder do atraso: ensaios de sociologia da história lenta. 2. ed. São Paulo: Hucitec.

MARTINS, José de Souza. (2000) Reforma agrária: o impossível diálogo. São Paulo: EDUSP.

MIGUEL, Maria Elisabeth Blanck. (2007) As escolas rurais e a formação de professores: a experiência do Paraná. In: WERLE, Flávia Obino Corrêa (Org.). Educação rural em perspectiva internacional: instituições, práticas e formação do professor. ljuí: Unijuí, p. 79-98.

MOLINA, Mônica Castagna. (2004) O Pronera como construção prática e teórica da Educação do Campo. In: ANDRADE, Marica Regina; DI PIERRO, Maria Clara; MOLINA, Mônica Castagna; JESUS, Sônia Meire Santos Azevedo de. A educação na reforma agrária: uma avaliação do Programa Nacional de Educação na Reforma Agrária. Brasília: Ação educativa, p. 61-88.

NOGUEIRA, Delane Lima. (2008) Amélia Xavier e a escola normal rural de Juazeiro do Norte: registros sobre a constituição de uma cultura docente para a educação no campo. Fortaleza, 2008. 200 f. Dissertação (Mestrado em educação) - Centro de Educação, Universidade Estadual do Ceará, Fortaleza.

QUEIROZ, Maria Aparecida de. (1984) A Questão Rural e os desacertos da educação: o caso de Ceará - Mirim. Campinas, 1984. 157 f. Dissertação (Mestrado em Educação) - Faculdade de Educação, Universidade Estadual de Campinas, Campinas, SP.

QUEIROZ, Maria Aparecida de. (1997) EDURURAL/NE no Rio Grande do Norte: o desafio de transformar a administração educacional municipal (1980/1985-1987). São Paulo, 1997. 173 f. Tese (Doutorado em Educação) - Faculdade de Educação - Programa de Pós-graduação em Educação, Universidade de São Paulo, São Paulo.

REIS, Douglas Sathler dos. (2006) O rural e o urbano no Brasil. In: ENCONTRO NACIONAL DE ESTUDOS POPULACIONAIS (ABEP), 15., 2006. Anais... Caxambú, MG, p. 1-18. 
RIBEIRO, Darcy. (2004) Reforma Agrária e João Goulart. Revista Pense Século 21, Natal, p. 28-30, jun.

SAVIANI, Dermeval. (2003) Escola e democracia: polêmicas de nosso tempo. 36. ed. Campinas: Autores Associados.

SILVA, Lourdes Helena; COSTA, Vânia Aparecida. Educação rural. (2006) Presença pedagógica, Belo Horizonte, v. 12, n. 69, p. 63-69, maio/jun.

SOUZA, José Nicolau de; CABRAL NETO, Antônio. (2004) Proposta pedagógica adaptada ao meio rural: educação das populações rurais como prioridade. In: CABRAL NETO, Antônio (Org.). Política Educacional: desafios e tendências. Porto Alegre: Sulina, p. 178-213.

VALE, Ana Rute do. O rural brasileiro frente à urbanização: velha ou nova ruralidade? (2005) in: SIMPÓSIO NACIONAL DE GEOGRAFIA AGRÁRIA, 3. SIMPÓSIO INTERNACIONAL DE GEOGRAFIA AGRÁRIA JORNADA ARIOVALDO UMBELINO DE OLIVEIRA, 2., 2005. Anais... Presidente Prudente.

VEIGA, José Eli da. et al. (2001) O Brasil precisa de uma estratégia de desenvolvimento. Brasília: MDA/CNDRS/NEAD.

WERLE, Flávia Obino Corrêa (Org.). (2007) Educação rural em perspectiva internacional: instituições, práticas e formação do professor. ljuí: Unijuí. 